\title{
COLOR DUPLICATION IN LITHIUM DISILICATE RESTORATIONS FABRICATED BY CAD-CAM USING VISUAL AND INSTRUMENTAL SHADE MATCHING SYSTEMS (IN VITRO STUDY)
}

\author{
Mohamed T. Rashidy ${ }^{1^{*}}$ BDS Ihab A. Hammad ${ }^{2}$ BDS, MS, $P h D^{\prime}$ Yehia S. Aboushady ${ }^{2}$ BDS, $M S, P h D$.
}

\begin{abstract} teeth. using visual and instrumental shade matching systems.

between the master and the fabricated ceramic discs were measured using the equation. $\Delta E=\sqrt{\left(L_{F}-L_{M}\right)^{2}+\left(a_{F}-a_{M}\right)^{2}+\left(b_{F}-b_{M}\right)^{2}}$ $(22.22 \pm 4.73)$ with a significant difference between them $\mathrm{p}<0.001$.

CONCLUSIONS: Visual shade selection using classical shade guide showed lower delta $E$ than that of instrumental shade matching using Easyshade.

KEYWORDS: Color duplication, lithium disilicate, E-max, Visual, Instrumental.

1 Instructor at Fixed Prosthodontics Department, Faculty of Dentistry, Pharos University in Alexandria, Egypt.

2 Professor of Fixed Prosthodontics, Conservative Dentistry Department, Faculty of Dentistry, Alexandria University, Egypt.
\end{abstract}

INTRODUCTION: Color reproduction is one of the most challenging issues encountered by clinicians because of the complexity of visual properties of natural

OBJECTIVES: This study aimed to assess color differences among intended and fabricated shades of lithium disilicate restorations fabricated by CAD-CAM after

MATERIALS AND METHOD: IPS Emax CAD blocks measuring (12.4mm width x $14.5 \mathrm{~mm}$ length x 18 mm thickness) were cut under continuous water irrigation using diamond-impregnated slicing wheels mounted on a slow-speed saw microtome (Isomet; Buehler) to yield 16 rectangular specimens measuring (12.4 x $14.5 \mathrm{x} 1.5 \mathrm{~mm}$ ). Then they were subjected to the crystallization cycle. Then IPS Emax glaze paste was applied with uniform thickness onto the crystallized specimen surface. Each master disk represented the color of a shade guide tab in the Vita Classic (16 shades). Shade selections for these master disks were carried out following visual and instrumental methods. Accordingly, 16 visual and 16 instrumental experimental disks were fabricated. After analysis, color differences $(\Delta \mathrm{E})$ RESULTS: On comparing Visual Emax CAD and instrumental Emax CAD, the mean $(\Delta \mathrm{E})$ for visual $(2.96 \pm 1.90)$ was lower than the mean $(\Delta \mathrm{E})$ for instrumental

*Corresponding author:

E-mail:mhmdtahaa92@gmail.com

\section{INTRODUCTION}

One of the critical parts of esthetic dentistry is color, which affects the patient's satisfaction concerning their restorations. Color reproduction is one of the most exciting issues encountered by clinicians due to the complexity of the visual properties of natural teeth (1).

The thickness of enamel, dentin 's reflection, and scattering leads to exterior color of natural teeth (2). Consequently, precise and reliable color reproduction needs consideration of the visual properties of teeth (2). Dental restorations' esthetics influenced by color and its essentials like hue, chroma, value, opacity, translucency, light transmission, scattering, metamerism, and fluorescence (3). The human eye can differentiate between non-natural and natural teeth, according to tiny variances in color and translucency $(2,3)$.

Visual analysis or instrumental evaluation can be used for shade determination. An almost commonly followed procedure of shade selection is visual color determination using shade guides; however, color replication through this method is overwhelmed by variable and unpredictable results $(4,5)$. The observer's physiologic and psychological responses to the reflected radiant-energy stimulus can affect the visual assessment. Color perception can be affected by Some variables, as peripheral light condition, preceding eye

exposure, object illuminant location, and metamerism, the observer's explanation of color stimulus influenced by other uncontrolled factors like exhaustion, aging, and emotions influence (5-8).

The color standard to which commercially manufactured shade guides coordinate with the color of the tooth. Nevertheless, studies stated that more than $80 \%$ of the patients prompt their disappointment with observable color variances(9). Consequently, instrumental colorimetric techniques have been introduced. there are generally one of three types: colorimeters, spectrophotometers, or digital color analyzers. A Spectrophotometer measures and records the amount of visible radiant energy reflected or transmitted by an object one wavelength at a time for each Value, Chroma, 
and Hue present in the entire visible spectrum. The extensive data obtained from the Spectrophotometers must be manipulated, and a data-reduction strategy employed, to translate the data into a useful format(6).

However, intraoral colorimetric cannot get into the same position on the same tooth due to suffering from edge loss (10). Furthermore, the instrumental color appraisal of teeth is not error-proof (10). Accordingly, the fabrication of a restoration that resembles the target shade is extremely challenging.

This study was intended to assess color differences among intended and fabricated shades of lithium disilicate restorations fabricated by CAD-CAM using visual and instrumental shade matching systems.

Null hypothesis: there is no color differences among intended and fabricated shades of lithium disilicate restorations fabricated by CAD-CAM using visual and instrumental shade matching systems.

\section{MATERIALS AND METHOD}

The study was conducted after receiving the approval of the ethical committee at the Faculty of Dentistry, Alexandria University, Egypt. (IRBNO:00010556IORG0008839).

Preparation of the study specimens

IPS Emax CAD blocks (Ivoclar-Vivadent, Schaan, Liechtenstein, Lithium disilicate glass-ceramic) measuring (12.4mm width $\mathrm{x} 14.5 \mathrm{~mm}$ length $\mathrm{x} 18 \mathrm{~mm}$ thickness) were cut under continuous water irrigation. This was performed using diamond-impregnated slicing wheels mounted on a slow-speed saw microtome (Isomet; Buehler) to yield 16 rectangular specimens measuring (12.4 x 14.5x $1.5 \mathrm{~mm})$. The discs which showed any discrepancies were avoided.

A split acrylic mold was fabricated with a rectangular hole of $12.4 \times 14.5$ diameter and $1.5 \mathrm{~mm}$ thickness similar to the dimensions of the disc specimens. It is composed of a base and 2 removable cylindrical and cubiform parts to facilitate the insertion and removal of the discs, this mold was used to fix the specimens during glazing.

After IPS Emax CAD blocks have been sliced, the specimens were cleaned for 3 minutes with ultrasound cleaner in a water bath; to eliminate any remaining residue on the surface, then they were subjected to crystallization cycle at $840^{\circ} \mathrm{C}$ for 25 minutes in the Programat $310 \mathrm{CS}$ furnace ( Ivoclar-Vivadent, Schaan, Liechtenstein.), and the material color changes from blue to tooth color due to meta-silicate phase is transported to the final lithium disilicate structure (Table 1). After 35 minutes, specimens were set off to cool down for 10 minutes over the tray, which stores the heat and thus allows the slow and tension-free cooling of the glassceramic material. After crystallization, the specimens were ready for glazing. A split acrylic mold was fabricated with rectangular hole of 12.4 x 14.5 diameter and $1.5 \mathrm{~mm}$ thickness similar to the dimensions of the disc specimens.This mold was used to fix the specimens during glazing. IPS Emax glaze paste was mixed and applied with uniform thickness. Subsequently, they were placed over the honey-comb glazefiring tray, and the proper glaze firing program was selected according to recommended firing parameters by the manufacturer (Table 1). Glazing cycle took place for 12 minutes in the same Programat ${ }^{\circledR}$ P310 furnace. Once the firing cycle was completed, the glazed specimens were left out of furnace for 10 minutes to cool down over the honeycomb tray, and finally, their thickness was confirmed using a caliper to be ready for testing. (Figure 1,2)

Table (1): Parameters for Glaze firing in Programat P310 furnace

\begin{tabular}{||c|c|c|c|c|c|c|c||}
\hline $\begin{array}{c}\text { Entry } \\
\text { time }\end{array}$ & $\begin{array}{c}\text { Entry } \\
\text { temp. }\end{array}$ & $\begin{array}{c}\text { Heating } \\
\text { rate }\end{array}$ & $\begin{array}{c}\text { Final } \\
\text { temp. }\end{array}$ & $\begin{array}{c}\text { Holding } \\
\text { time }\end{array}$ & $\begin{array}{c}\text { Lower } \\
\text { table }\end{array}$ & $\begin{array}{c}\text { Start } \\
\text { vacuum }\end{array}$ & Release \\
Vacuum \\
\hline $\begin{array}{c}6: 00 \\
\text { min }\end{array}$ & $400^{\circ} \mathrm{C}$ & $\begin{array}{c}30^{\circ} \mathrm{C} / \\
\min \end{array}$ & $840^{\circ} \mathrm{C}$ & $\begin{array}{c}10: 00 \\
\min \end{array}$ & $700^{\circ} \mathrm{C}$ & $550^{\circ} \mathrm{C}$ & $840^{\circ} \mathrm{C}$ \\
\hline
\end{tabular}

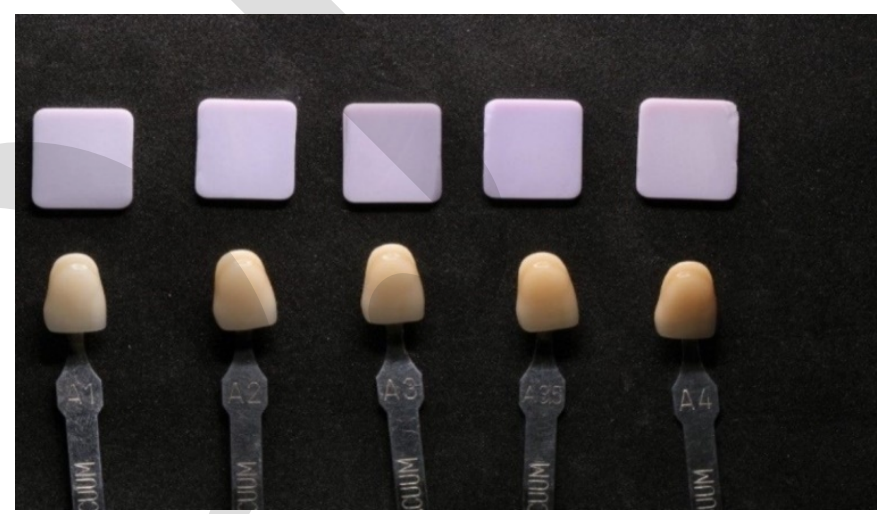

Figure 1: Emax before crystallization.

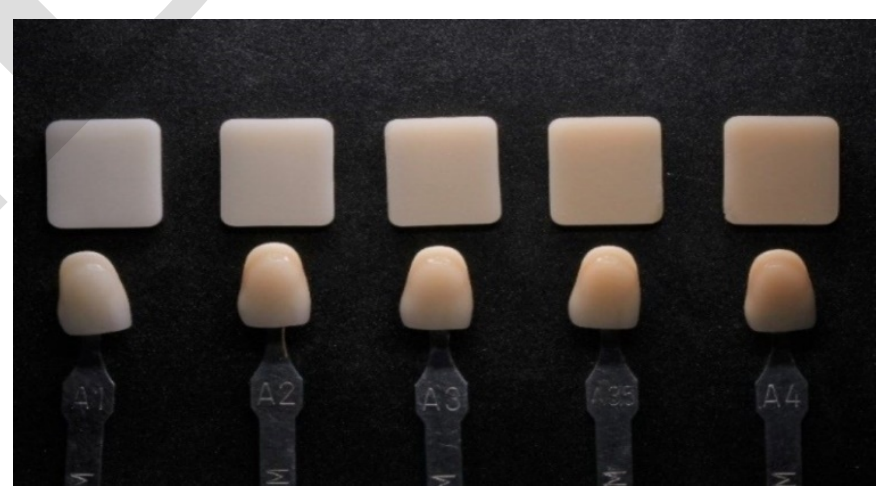

Figure 2: Emax after crystallization and glazing.

\section{1-Visual analysis}

Visual shade matching procedures were achieved using Vita Classical shade guide under meticulous illumination circumstances with an unchanging non-natural light source (Ney-Lite- 7000 0K; J.M. Ney Co, Bloomfield, Conn). To diminish lumen diminution, the effect of ambient light, and to reduce the possibility of retinal fatigue; The source of light was approximately 2 feet away from the study samples, and a 10 seconds time limit was set for shade evaluation. The background was a neutral gray background to decrease the opportunity of mistakes resulting from contrast 
(successive or simultaneous) and after image (positive or negative).

The selections were made by10 female examiners (dentists with a master degree in fixed prosthodontics ) of the same age group (25-35 years) and educational background. Each clinician was tested for color blindness by the Ishihara color blindness test to reduce possible mistakes resulting from imperfections in color vision between observers.

Choice was based on an agreement between 6 or more of the 10 examiners or on agreement between the 10 examiners when 10 unique shades were selected. The most repeated readings among all the observers were the final choice. (Figure 3)

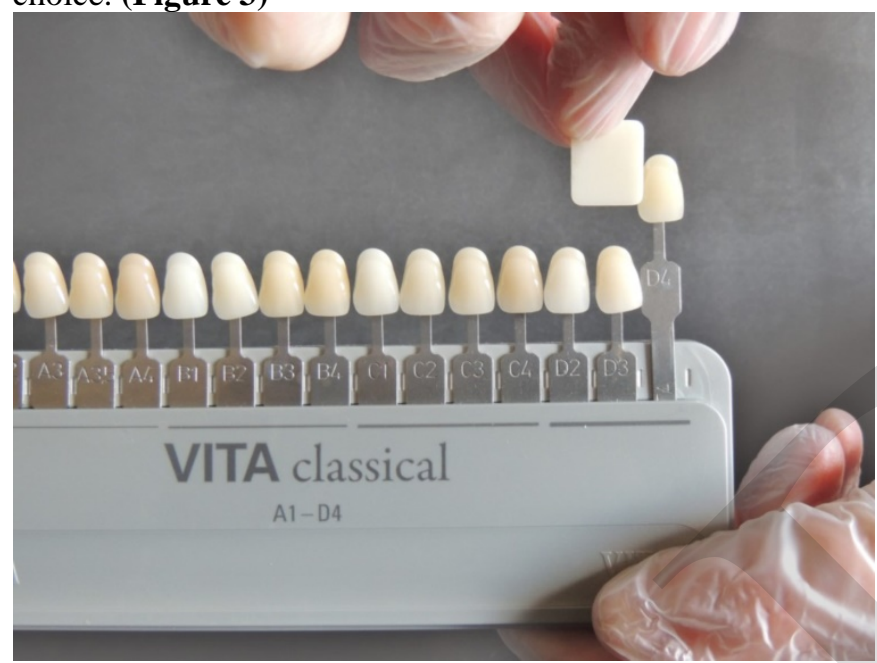

Figure 3: Visual selection by the examiner using vita classical shade guide

The readings were collected and 16 fabricated discs were produced according to selected shades by examiners for each master disk, then transformed to (CIE $\mathrm{L}^{*} \mathrm{a}^{*} \mathrm{~b}^{*}$ ) standards by spectral reflectance values from the spectrophotometer.

\section{Spectrophotometer analysis}

For this study, color coordinates (CIE $\mathrm{L}^{*} \mathrm{a}^{*} \mathrm{~b}^{*}$ ) were determined. A computer color matching system (UV. Shimadzy 3101 PC) was used for the spectrophotometric assessment of the specimens. Measurements were done in the Photometry Department (National Institute of Standards; Tersa St., El-Haram, Giza, Egypt). The spectrophotometric analysis of the specimens was done using a reflectance spectrophotometer with specimens placed against white and black backgrounds.

Measurements were made for Specimens of master discs by the spectrophotometer and used as a control for color parameters CIE $\mathrm{L}^{*} \mathrm{a} * \mathrm{~b} *$ as the manufacturer of Vita Zahnfabrik, Bad Säckingen, Germany was contacted and stated that they don't provide the CIE $\mathrm{L}^{*} \mathrm{a}{ }^{*} \mathrm{~b} *$ or Lch values for the original VITA classical A1- D4 shade tabs.

And that reproducibility of color parameters to be used as a reference from the machine is only available under standard conditions.

Spectrophotometer was used to evaluate the color parameters for the visual group's fabricated discs only, As for the instrumental shade selection the color parameters were collected from the Vita Easyshade device.

Fabricated group resulting in CIE L*a*b* were compared to that of the master discs color parameters obtained by the spectrophotometer.

\section{2- Instrumental analysis}

The color was evaluated using a clinical spectrophotometer (VITA Easy shade Compact).. VITA Easy shade is a spectrophotometer with a $5 \mathrm{~mm}$ diameter tip consisting of nineteen $1 \mathrm{~mm}$ fiber optic bundles. Spectral light reflectance is measured in $25 \mathrm{~nm}$ wavelength bandwidths.

Calibration was performed by placing the examination tip on the calibration port aperture before each specimen measurements. There are four options in the measurement style menu: Tooth areas, Tooth single, Restoration, and Shade Tab. "Tooth single" mode was selected to measure the base shade by holding the probe tip at $90^{\circ}$ to the surface of each specimen.

Each specimen was placed over white $\left(\mathrm{L}^{*}=71.7, \mathrm{a}^{*}=\right.$ $\left.1.5, b^{*}=3.2\right)$ and black $\left(L^{*}=73.3, a^{*}=-1.6, b^{*}=3.2\right)$ tiles while placing the glazed surface upward and "tooth single" mode was selected. (Figure 5)

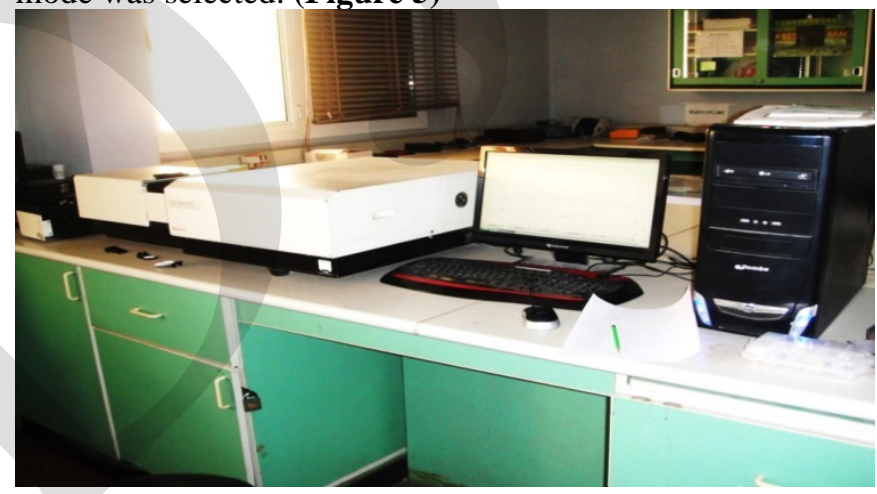

Figure 4: Spectrophotometer unit 3101 PC

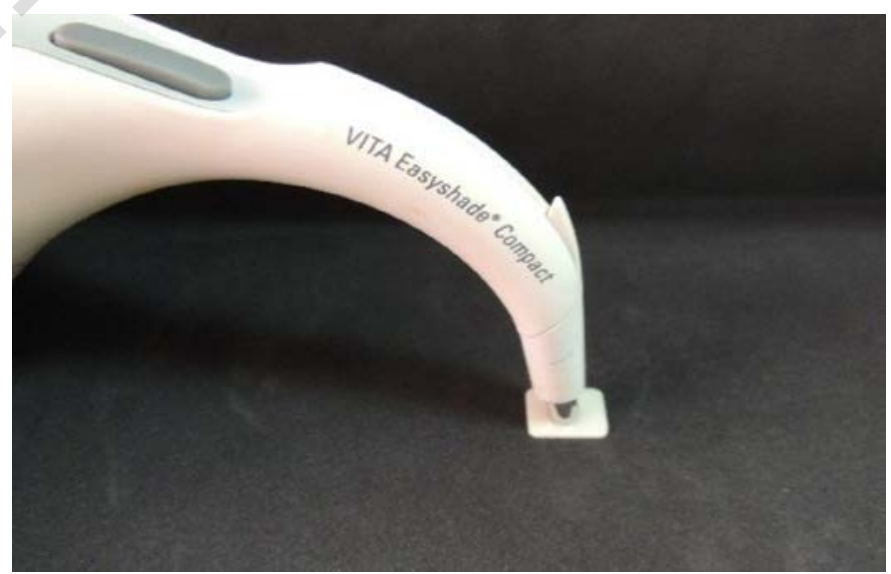

Figure 5: Instrumental shade selection using vita Easyshade

Measurements for each specimen were repeated three times on each background and the mean CIE L*a*b* values were recorded for both backgrounds.

Collection of instrumental shade selections data by Vita Easyshade and were compared to the readings of CIE 
$\mathrm{L}^{*} \mathrm{a}^{*} \mathrm{~b}^{*}$ values of the master discs that collected from spectrophotometer with the use of the equation:

$$
\Delta E=\sqrt{\left(L_{F}-L_{M}\right)^{2}+\left(a_{F}-a_{M}\right)^{2}+\left(b_{F}-b_{M}\right)^{2}}
$$

\section{Color Difference Measurement}

After visual and instrumental analysis color measurement of the master and fabricated discs were performed using a Vita Easyshade and Spectrophotometer (U.V., shimadzy 3101 PC - Spectrophotometer, Japan.). The CIELAB coordinates ( $\mathrm{L}^{*}, \mathrm{a}^{*}$, and $\mathrm{b}^{*}$ ) were calculated for each of the ceramic discs.

Color differences $(\Delta \mathrm{E})$ between the master and the fabricated ceramic discs was determined with the use of the equation:

$$
\Delta E=\sqrt{\left(L_{F}-L_{M}\right)^{2}+\left(a_{F}-a_{M}\right)^{2}+\left(b_{F}-b_{M}\right)^{2}}
$$

Where the fabricated (F) and master (M) are color descriptors.

\section{Statistical analysis}

Data fed to the computer and investigated using IBM SPSS software package version 20.0. (Armonk, NY: IBM Corp) Qualitative data were described by number and percent. The Kolmogorov-Smirnov test was utilized to verify the normality of distribution. Quantitative data were termed using range (minimum and maximum), mean, standard deviation, and median. The significance of the acquired results was adjusted at the $5 \%$ level.

The used tests were F-test (ANOVA) to compare the quantitative data between the tested groups, and Post Hoc test (Tukey) for pairwise comparisons.

\section{RESULT}

A total of differences for $\mathrm{L}^{*}, \mathrm{a}^{*}$, and $\mathrm{b}^{*}$ were calculated. The total color difference $(\Delta \mathrm{E})$ were compared statistically.

Descriptive statistics for CIE L*a*b* (mean, standard deviation, standard error, minimum, and maximum) are presented in (Table 2).

On comparing Visual Emax CAD and instrumental Emax CAD, the mean delta $\mathrm{E}$ for visual $(2.96 \pm 1.90)$ was lower than the mean delta $E$ for instrumental $(22.22 \pm 4.73)$ with a significant difference between them $\mathrm{p}<0.001$.

The mean color differences between the master and the fabricated ceramic discs for the different systems are shown in (Figure 6).

Table (2): Comparison between the different studied groups according to Delta E of intended and fabricated Emax CAD.

\begin{tabular}{|c|c|c|c|c||}
\hline & $\begin{array}{c}\text { Visual } \\
\text { Emax CAD } \\
(\mathbf{n = 1 6 )}\end{array}$ & $\begin{array}{c}\text { Easy shade } \\
\text { Emax CAD } \\
(\mathbf{n = 1 6})\end{array}$ & $\mathbf{F}$ & $\mathbf{p}$ \\
\hline Min. - Max. & $0.47-6.67$ & $15.43-31.85$ & & \\
Mean \pm SD. & $2.96 \pm 1.90$ & $22.22 \pm 4.73$ & $151.883^{*}$ & $<0.001^{*}$ \\
Median (IQR) & 2.53 & 22.3 & & \\
$(1.69-4.19)$ & $(18.3-25.35)$ & & \\
\hline Sig. bet. groups & \multicolumn{2}{|c|}{$\mathrm{p}_{1}<0.001^{*}$} & & \\
\hline
\end{tabular}

F: F for ANOVA test, Pairwise comparison bet. each 2 groups was done using Post Hoc Test (Tukey) p: p-value for comparing between the different studied groups

$\mathrm{p}_{1}$ : $\mathrm{p}$-value for comparing between Visual Emax CAD and instrumental (Easyshade) Emax CAD

*: Statistically significant at $\mathrm{p} \leq 0.05$

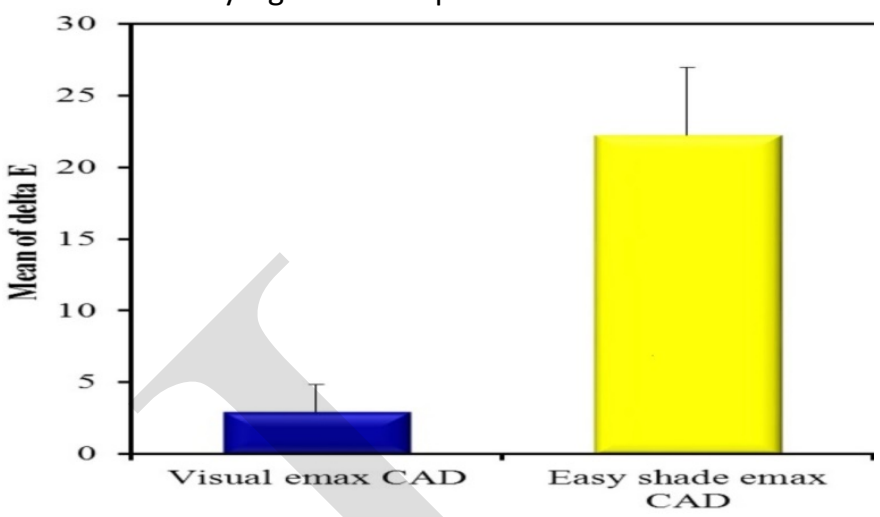

Figure 6: Comparison between the different studied groups according to Delta E of intended and fabricated Emax CAD.

\section{DISCUSSION}

As the patient's demands for improvement of appearance are continuously increasing, the use of esthetic restorations becomes widely required (11), shade selection in dentistry was reported to be via two common methods, visual and instrumental. Even though color measurements by evaluation between patient's teeth and standard shade guide is the most popular procedure, the individual variations between dentists, shade guides, and technicians impair standardization and make tooth color selection a very critical matter. It is also affected by many other factors following occasional faults in appearance resembling of restoration to natural teeth as the traditional shade selection process is a subjective evaluation even under ideal condition (12-14).

Color assessment in dentistry can be determined by visual shade selection, which is the most frequently used technique. It is a complicated method that includes subjective and objective phenomena. Studies have reported an absence of reliability among and inside examiners over time; also, this procedure is overwhelmed by variable and unpredictable outcomes $(5,15)$.

Factors as gender and age can influence a color assessment procedure as it is not constant between different clinicians $(8,10)$. To achieve consistency, In this study, all selected clinicians were females in the same age group and have the same educational background $(10,16)$. The most repeated readings among all the observers were the final choice.

Shade matching procedures were performed with a neutral gray background (10) and under meticulous illumination circumstances with an unchanging non-natural light source. The light source was kept approximately 2 feet away from the sample (17).

A color booth should be used to ensure the reliability of the light source; nevertheless, it was expected that the 
clinical condition would be more meticulously approached with the use of illumination source accessible at most clinical set up (10).

In the present study, the Vita Easyshade clinical spectrophotometer was used to evaluate the color of the teeth instrumentally. The Vita Easyshade was reported to have 92.6\% accuracy and 96.4\% reliability when compared with different electronic shade matching devices (18).

A computer color matching system (spectrophotometer) was used as a standard control as it is stable over time (19). Also, it converted the values of the visual assessment into CIE L*a*b* color space. However, a spectrophotometer is quite stable over time, whereas it's limiting factors are their high cost and complexity of handling (19).

The CIE $\mathrm{L}^{*} \mathrm{a} \mathrm{b}^{*}$ color space was selected as it is an recognized technique for differential color measurements in dentistry (20). Also it enabled us to reliably quantify the color of teeth by measuring color and expressing it in terms of three coordinate values $\left(\mathrm{L}^{*} \mathrm{a}^{*}\right.$ and $\left.\mathrm{b}^{*}\right)$ which locate the object's color in CIE $\mathrm{L}^{*} \mathrm{a} * \mathrm{~b} *$ color space.

The numeric explanation of color permits the specific description of the magnitude of color variance among objects rather than the visual matching which is restricted only to the determination of noticeable mismatch (19-21).

Kuehni $\mathrm{R}$ and Marcus $\mathrm{R}$ (22) stated that $\Delta \mathrm{E}=1$ is supposed to be a color difference appreciable by observers.

Ragain J and Johnston W (23) stated that color difference $\Delta \mathrm{E}>2.75$ is supposed to be unacceptable and these standards are considered clinically acceptable over the $3.3 \Delta \mathrm{E}$ described by Ruyter et al. (24) due to their procedure for gaining the color difference could not be proved (15).

Johnston and Kao (25) stated color validity in a clinical study and described an average $6.8 \Delta \mathrm{E}$ between composite veneered teeth and adjacent natural teeth and considered as a difference but was still within the normal range. This value was an average within a range of 1.3 to 13.1 $\Delta \mathrm{E}$, which could have resulted from using a colorimeter where the edge loss effect was not put into consideration (15). Accordingly, this could have caused inaccuracies; however, their results stated that color difference higher than $2.75 \Delta \mathrm{E}$ between a restoration and adjacent natural teeth in an actual clinical scenario is unacceptable.

In this study, the Easyshade showed significantly higher mean $\Delta \mathrm{E}$ values due to different absolute calibration mood between Easyshade and the spectrophotometer (26).

Although the Easyshade manufacturer has claimed that it eliminates any dependence on human vision and gives accurate results, it still suffers from limitations. The instrument is a small window spectrophotometer, which means it has a very small aperture through which both the illuminant light and the reflected light must pass. Smallwindow instruments can be inaccurate due to the effects of edge loss, a phenomenon that occurs during conventional reflectance measurements of translucent materials like natural teeth and ceramic materials. Light from the illuminant travels through and exits off the translucent material. Thus, only part of the illuminant enters back into the window where reflectance is measured via the observation light path and some of the signal is lost. Furthermore, due to the instrument's extreme accuracy which could mislead the most experienced clinician, different readings could be recorded within the same 1-2 mm distance in any tooth or sample(10). These limitations might be the reason behind the significantly higher $\Delta \mathrm{E}$ obtained compared to those obtained from visual shade matching systems.

The instrument has a small spectrophotometer window, which means the illuminant light and the reflected light pass through a tiny hole. As the consequence of edge loss, this may be inaccurate (27.28), throughout regular reflectance measurements of translucent materials like natural teeth and ceramic materials, this phenomenon could occur. Light from the illuminant travels into and exits off the translucent material. Accordingly, reflectance is assessed with the observation light pathway, and a portion of the illuminant go back into the window, then some of the signal is lost $(29,30)$. Furthermore, different readings could be noted in the same 1-2 $\mathrm{mm}$ distance of sample, due to the instrument's extreme accuracy, which could deceive qualified clinicians (10).

On the other hand, the visual method showed the lowest mean $\Delta \mathrm{E}$ values. This might be attributed to the process of visual color assessment.

Both methods showed an agreement with spectrophotometer regarding $\mathrm{L}^{*} \mathrm{a} \mathrm{b}^{*}$ values in this study, and this agreement was not statistically significant. The arrangement between the visual process and Easyshade device with a spectrophotometer was almost the same. This comes following $\mathrm{Li}$ et al. $(31,32)$ they concluded that no absolute superiority for instrumental method over the visual method. Same as Okubo et al. (5), they found that instrumental was slightly better than visual; however, both studies were using colorimeter rather than spectrophotometer.

If $\Delta \mathrm{E}>2.75$ is reported as a clinically unacceptable color difference (25), then this study found no clinically significant differences between groups concerning $\Delta \mathrm{E}$, with all $\Delta \mathrm{E}$ values falling within the clinically unacceptable range.

The results of the present study are consistent with a previous study by Wee et al. (15) in which variation of color among intended matched shades and fabricated shades of dental porcelain were evaluated using the same visual shade matching systems and a different instrumental shade matching device. The results are also consistent with another study (30) where color matches among extracted teeth and final fabricated porcelain shade tabs were assessed by examiners using the same shade evaluation techniques used in the present study.

Also, the results of the present study are constant with a previous study (17) in which variation of color between intended matched shades and fabricated shades of metalceramic complexes were evaluated using visual and instrumental shade-matching systems.

In this study $\Delta \mathrm{E}$ obtained in all systems was relatively lower than those obtained in Wee et al. (15), and this might be due to the examiners participated in this study were all 
female prosthodontists with the same experience in shade matching procedures. However, the examiners selected by Wee et al. (15) were of different educational backgrounds and experiences (a general dentist, a prosthodontist, and a maxillofacial prosthodontist). Also Wee et al. (15) fabricated their master discs from unknown shades selected randomly. Therefore, the color of the master discs was not equally distributed in the tooth color space. To maximize the coverage of the tooth color space in the present study, master discs represented all shades of the shade guides used.

Thus the null hypothesis was rejected in this study finding significant color difference between intended and fabricated shades of lithium disilicate restorations fabricated by CAD/CAM using visual and instrumental shade matching systems.

\section{CONCLUSIONS}

Within the confines of this study, it could be concluded that:

1. Visual shade selection showed lower delta $E$ than that of instrumental shade matching using the Easyshade shade guide.

2. The color difference between intended and fabricated shades was clinically unacceptable using both visual and instrumental shade matching systems.

\section{CONFLICT OF INTREST}

The authors declare that they have no conflict of interest.

\section{REFERENCES}

1. Vichi A, Louca C, Corciolani G, Ferrari M. Color related to ceramic and zirconia restorations: a review. Dent Mater. 2011;27:97-108.

2. Seghi RR, Johnston WM, O'Brien WJ. Spectrophotometric analysis of color differences between porcelain systems. J Prosthet Dent. 1986;56:35-40.

3. Ilie $\mathrm{N}$, Hickel $\mathrm{R}$. Correlation between ceramics translucency and polymerization efficiency through ceramics. Dent Mater. 2008;24:908-14.

4. Culpepper WD. A comparative study of shade-matching procedures. J Prosthet Dent. 1970;24:166-73.

5. Okubo SR, Kanawati A, Richards MW, Childressd S. Evaluation of visual and instrument shade matching. J Prosthet Dent. 1998;80:642-8.

6. Paul SJ, Peter A, Rodoni L, Pietrobon N. Conventional visual vs spectrophotometric shade taking for porcelainfused-to-metal crowns: a clinical comparison. J Prosthet Dent. 2004;92:577.

7. Van der Burgt TP, Ten Bosch JJ, Borsboom PC, Plasschaert AJ. A new method for matching tooth colors with color standards. J Dent Res. 1985;64:837-41.

8. Preston JD, Bergen SF. Color science and dental art, St. Louis: CV Mosby Company; 1980.

9. Kawaragi C, Ishikawa S, Miyoshi F, Furukawa K, Ishibashi K. Evaluations by dentists and patients concerning the color of porcelain-fused-to-metal restorations. Dent J Iwate Med Univ. 1990;15:9-17.
10. Hammad IA. Intrarater repeatability of shade selections with two shade guides. J Prosthet Dent. 2003;89:50-3.

11. Brewer JD, Wee A, Seghi R. Advances in color matching. Dent Clin North Am. 2004;48:v-341.

12. Barath VS, Faber FJ, Westland S, Niedermeier W. Spectrophotometric analysis of all-ceramic materials, and their interaction with luting agents and different backgrounds. Adv Dent Res. 2003;17:55-60.

13. Carsten DL. Successful shade matching--what does it take?. Compend Contin Educ Dent. 2003;24:175-8.

14. Meng X, Yoshida K, Atsuta M. Hardness development of dual-cured resin cements through different thicknesses of ceramics. Dent Mater J. 2006;25:132-7.

15. Wee AG, Monaghan P, Johnston WM. Variation in color between intended matched shade and fabricated shade of dental porcelain. J Prosthet Dent. 2002;87:657-66.

16. Haddad HJ, Jakstat HA, Arnetzl G, Borbely J, Vichi A, Dumfahrt H, et al. Does gender and experience influence shade matching quality? J Dent. 2009;37:e40-4.

17. Al-Hamdan EM, Hammad IA, Tashkandi E. Evaluation of color duplication in metal-ceramic complexes using visual and instrumental shade-matching systems. Int J Prosthodont. 2010;23:149-51.

18. Ram S. Accuracy of the easy shade clinical spectrophotometer with shade guides. J Dent Res. 2007;86A:1639.

19. CIE C. Official recommendations of the International Commission on illumination. Publication CIE No. 15.2. 1986.

20. Douglas RD, Przybylska M. Predicting porcelain thickness required for dental shade matches. J Prosthet Dent. 1999;82:143-9.

21. L'Eclairage CI. CIE recommendations on uniform color spaces, color-difference equations, and metric color terms. Color Res Appl. 1977;2:5-6.

22. Kuehni RG, Marcus RT. An experiment in visual scaling of small color differences. Color Res Appl. 1979;4:83-91.

23. Ragain Jr JC, Johnston WM. Color acceptance of direct dental restorative materials by human observers. Color Res Appl. 2000;25:278-85.

24. Ruyter IE, Nilner K, Möller B. Color stability of dental composite resin materials for crown and bridge veneers. Dent Mater. 1987;3:246-51.

25. Johnston WM, Kao EC. Assessment of appearance match by visual observation and clinical colorimetry. J Dent Res. 1989;68:819-22.

26. Corciolani G, Vichi A. Repeatability of colour reading with a clinical and a laboratory spectrophotometer. International Dentistry S A. 2006;8:62-70.

27. Bolt RA, ten Bosch JJ, Coops JC. Influence of window size in small-window color measurement, particularly of teeth. Phys Med Biol. 1994;39:1133-42.

28. Ragain JC, Johnston WM, Wan Q. Comparison of color between composite resin and shade guides. J Dent Res. 1996;75:2899.

29. Wee AG, RANG EY, Johnston WM, Seghi RR. Evaluating porcelain color match of different porcelain 
shade-matching systems. J Esthet Restor Dent. 2000;12:271-80.

30. Paravina RD, Ronald E . Understanding Color. J Gold Esth Dent. 2018;20:270-94.

31. Li Q, Wang YN. Comparison of shade matching by visual observation and an intraoral dental colorimeter. J Oral Rehabil. 2007;34:848-54.

32. Kalantari MH, Ghoraishian SA, Mohaghegh $M$. Evaluation of accuracy of shade selection using two spectrophotometer systems: Vita Easyshade and Degudent Shadepilot. J Eur Dent. 2017;11:196-2. 